\title{
FOREWORD
}

\section{Attention and Neurological Disorders}

"P ay attention!" says the teacher to a daydreaming student. "Are you paying attention?" asks the wife who's reviewing the weekend plans with her seemingly distracted husband. "Attenshun!" shouts the lieutenant to his troops. "I wasn't paying attention," explains the motorist who backed into a fence. These examples serve to highlight the practical, everyday importance of attention. It is an often-mentioned human behavior because we all seem to appreciate that processing of any form of environmental information requires us to attend to that information. Most "accidents" are caused by failures or decrements of attention. This fact is now welldocumented by studies of motorists using cellular telephones. Furthermore, attention is basic to all learning. As attention for new, incoming stimuli decreases, learning decreases. Clinicians recognize that all forms of therapy involve some form of learning. If the individual receiving treatment is not relegating the amount and type of attention required by a task, then incomplete, incorrect, or even no learning takes place. We also recognize that tests of other domains of cognition, such as language and executive skills can yield invalid assessments of those skills secondary to attentional deficits.

Clearly, the cognitive domain of attention is one of critical importance to purposeful human activity. According to Parasuraman, ${ }^{1}$ however, "Attention is not a single entity, but the name given to a finite set of brain processes that can interact, mutually and with other brain processes, in the performance of different perceptual, cognitive, and motor tasks." To accurately assess "attention" and successfully treat disorders of attention, therefore, clinicians must recognize and understand all attentional processes. To help clarify these concepts, we decided to dedicate a volume of Seminars in Speech and Language to this topic. To serve as Guest Editor for this volume, I called upon Dr. Laura Murray, because I am very familiar with her excellent work in the realm of attention and aphasia. Dr. Murray graciously agreed to the task and put together a team of contributors to address the full range of considerations, including descriptions of forms of attention, the neuroanatomy of attention, the neuropathology of attention disorders in specific populations of brain-damaged adults, and the assessment and treatment of these disorders.

As readers will learn, there is quite a bit more to attention than is generally appreciated, but even an understanding of various normal attentional processes is not sufficient for optimal clinical practices. It is also important to be alert to the types of attentional problems most likely to occur as a result of various neurological disorders such as left hemisphere and right hemisphere strokes, traumatic brain injury and Alzheimer's disease. Then, clinicians must be prepared to evaluate and differentially diagnose attentional impairments so as to choose or develop appropriate management and therapy techniques. I am confident that this volume will provide readers with information for improving their clinical practices vis-à-vis the cognitive domain of attention.

Nancy Helm-Estabrooks, Sc.D. Co-Editor in Chief

Attention: Its Neuroanatomical Bases, Forms, Disorders, Assessment, and Treatment in Adults with Specific Neurological Disorders; Editors in Chief, Nancy Helm-Estabrooks, Sc.D., and Nan Bernstein Ratner, Ed.D.; Guest Editor, Laura L. Murray, Ph.D. Seminars in Speech and Language, volume 23, number 2, 2002. ${ }^{1}$ Aphosia Research Center, Boston VA Healthcare System, Boston, Massachusetts. Copyright (C) 2002 by Thieme Medical Publishers, Inc., 333 Seventh Avenue, New York, NY 10001, USA. Tel: +1(212) 584-4662. 0734-0478,p;2002,23;02,085,086,ftx,en;ss100108x. 


\section{REFERENCE}

1. Parasuraman R. The Attentive Brain. Cambridge, MA: MIT Press; 1998 